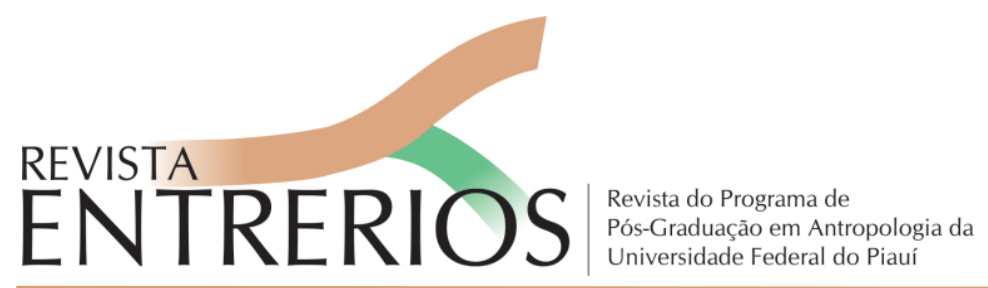

\title{
Interculturalidade e os desafios da inclusão dos Warao
}

\author{
Interculturalidad y desafíos de la inclusión de warao
}

\author{
Carmen Lúcia Silva Lima \\ Doutora em Antropologia - UFPE \\ Professora da Universidade Federal do Piauí - UFPI \\ carmen.lima@ufpi.edu.br
}

\begin{abstract}
Resumo: O presente artigo reflete sobre a situação dos Warao em Teresina, capital do Piaui, e analisa os desafios enfrentados em termos de ações de acolhimento e proteção. Utilizando dados etnográficos, aborda o contex to e as relações estabelecidas, evidenciando a necessidade da interculturalidade como um princípio que permitirá o respeito à especificidade sociocultural deste povo e a superação dos entraves que impedem a efetivação dos direitos que eles possuem. O argumento sustentado é que para serem eficazes, as ações do poder público e de outras instituições deverão respeitar o protagonismo dos Warao e precisarão ser gestadas $e$ desenvolvidas através do diálogo intercultural, que é uma exigência para a construção de uma convivência democrática e inclusiva.
\end{abstract}

Palavra-chave: indígenas Warao-interculturalidade-diálogo intercultural.

Resumen: En este artículo se reflexiona sobre la situación de los warao en Teresina, capital de Piaui, analizando los desafíos enfrentados en términos de acciones de recepción y protección. Basándose en datos etnográficos, aborda el contexto y relaciones establecidas, destacando la necesidad de la interculturalidad como principio que permitirá respetar la especificidad sociocultural de este pueblo-superando los obstáculos que impiden la puesta en vigor de los derechos que posee. El argumento es que, para ser eficaces, las acciones del poder público y otras instituciones deben respetar el protagonismo de los warao, siendo imprescindible sean gestionadas y desarrolladas por medio del diálogo intercultural, requisito imprescindible para la construcción de una convivencia democrática inclusiva.

Palabras clave: Indígenas Warao - interculturalidad - diálogo intercultural 


\title{
Começando o diálogo
}

Desde que os Warao chegaram à Teresina, tenho acompanhado diversas ações voltadas ao acolhimento e assistência desta coletividade. Ao longo deste processo, venho refletindo sobre a necessidade de construir relações interculturais, para favorecer à superação dos impasses e conflitos que têm emergido na relação estabelecidas entre os Warao e os não indígenas, principalmente com os agentes do poder público, que estão atuado diretamente nas ações de abrigamento em nossa capital.

Vale ressaltar que no Brasil, assim como em outros países, temos uma vasta literatura que mostra a aplicação do princípio da interculturalidade em diversas áreas, com resultados bastante positivos em termos de análise e aplicação, principalmente, no campo da antropologia e educação indígena (MATO, 2008; SOUZA LIMA, SANTOS e RIBEIRO, 2018; BARTOLOMÉ, 2006 e 2017; CANDAU e RUSSO, 2020; WALSH, 2007a, 2007b, 2008, 2009, 2010 e 2019; NASCIMENTO, QUADROS e FIALHO, 2016; NASCIMENTO, 2017). Defendo nesse artigo a necessidade da aplicação desta perspectiva nas ações desenvolvidas com os Warao, considerando que a "interculturalidade é uma maneira de se comportar, de conviver procurand o manter relações simétricas e de valorizar e fortalecer as identidades étnicas para que os povos indígenas se apresentem e façam frente aos conflitos que a diversidade produz" (BELTRÃO, 2018: 275).

A posição que adoto é distinta da abordagem multicultural, pois "O reconhecimento de e a tolerância para com os outros que o paradigma multicultural promete não só mantêm a desigualdade social como deixa intacta a estrutura social e institucional que constrói, reproduz e mantém essas desigualdades (WALSH, 2019: 24). A interculturalidade defendida

\begin{abstract}
es un imperativo político, que parte de una perspectiva que asume la diferencia cultural no sólo como un valor, sino como um dato constitutivo de una realidad dada. Al ser la pluralidad cultural um hecho fáctico, su existencia no requiere ser moralmente argumentada, sino entendida en función de la calidad diferencial específica de los actores intervinientes. Un diálogo intercultural equilibrado e igualitário debería constituirse como el mecanismo articulatorio normal de uma sociedad plural. No se trata de proponer una utopía social, sino de la necesidad lógica de un sistema de esta naturaleza, que debe superar los múltiples obstáculos que encuentra. (BARTOLOMÉ, 2017:145).
\end{abstract}

Para desenvolver a minha argumentação, utilizarei o relato etnográfico para descrever o cenário que se constituiu com a chegada dos Warao na capital piauiense e as relações estabelecidas. Na medida em que a exposição for sendo efetivada, evidenciarei os desafios, os impasses e os conflitos vivenciados por eles. Isso permitirá ao leitor entender a importância e a necessidade da interculturalidade nas ações de assistência e abrigamento que estão sendo desenvolvidas, para que possamos construir uma convivência democrática.

\section{Os Warao em Teresina}

Os Warao chegaram à capital piauiense no dia 12 de maio de 2019, em situação de bastante vulnerabilidade, causando preocupação para o poder público e a sociedade civil, que até então não havia estabelecido contato com indígenas migrantes refugiados ${ }^{1}$ da Venezuela. Inicialmente, chegaram 52 pessoas, mas logo em seguida vieram outras famílias, totalizando em julho, apenas dois meses depois, cerca de 200 indígenas na cidade.

1 MARIN e JUNIOR (2020) apresentam críticas bastante consistentes às categorias classificatórias migrantes e refugiados. 
Os Warao são originários da região nordeste da Venezuela, localizados majoritariamente nos estados de Monagas, Sucre e Delta do Amacuro, sendo este o que abriga o maior contingente populacional nos municípios de Tucupita, Pedernales, Casacoima e Antonio Dias. O censo do ano de 2011, realizado pelo Instituto Nacional de Estatística da Venezuela ${ }^{2}$, informa a existência de 48.771 indígenas desta etnia. É o segundo povo mais números, ficando atrás apenas do Wayuu/Guajiro. São tradicionalmente coletores, pescadores, agricultores e exímios artesãos. Da fibra do buriti e arrumã produzem diversos artefatos tais como peneiras, cestas, carteiras, chapéus e redes. Com missangas confeccionam colares e pulseiras ${ }^{3}$.

De acordo como os próprios Warao, a migração para ao Brasil está ocorrendo devido as dificuldades de sobrevivência na Venezuela. Desta forma, eles buscam melhores condições de vida. Segundo o indígena Aníbal Perez Cardona (2020), no ano de 1965, a vida de seu povo foi severamente impactada pelo Governo da Venezuela, que construiu uma barragem que represou o Rio Manamo. Este empreendimento produziu a salinização das águas e transformou severamente o ecossistema. Em decorrência, passaram a viver com grande dificuldade devido à escassez e extinção de espécies animais e vegetais. Esse problema socioambiental obrigou muitas famílias a se deslocarem do território originário para diversas cidades venezuelanas.

Outras adversidades também impactaram os Warao. Em 1992, no estado do Delta do Amacuro, eles tiveram muitos óbitos em decorrência de um surto de cólera. Neste momento, novos deslocamentos foram realizados devido ao adoecimento da população. A partir de 2014, a crise econômica, política e social que afetou a Venezuela se intensificou, produzindo a migração para o Brasil.

Já entre os anos de 2014 e 2016, especialmente, os/as Warao passaram a se deslocar para outros países, como o Brasil, porque a Venezuela vive uma crise econômica profunda, com escassez de alimentos, remédios, peças para a reposição de motores de popa e gasolina.

Com a crise, já não encontrávamos dinheiro em espécie nas agências bancárias. Quando conseguíamos, ele não tinha valor. O salário mínimo não era suficiente para comprar um par de sapatos. Havia alguns produtos básicos, mas com preços altíssimo, que não podíamos pagar. Assim, muitas famílias Warao foram obrigadas a sair do país porque a situação da Venezuela é insuportável. Saímos em busca de um contexto melhor - uma vida digna (CARDONA, 2020:7).

Em 2016, os deslocamentos foram intensificados; contundo, prevaleceram na região Norte $^{4}$ e somente em 2019, os Warao seguem para o Nordeste e passam a estar presentes em todas as regiões do país.

Hoje, há núcleos Warao em Pacaraima, Boa Vista, Manaus, Rio Branco, Santarém, Belém e em outras 18 cidades do Pará. Também há famílias em quase toda a região Nordeste (Imperatriz, São Luís, Teresina, Mossoró, Natal, Campina Grande, João Pessoa, Recife) e em diversas outras cidades do país, como Rio de Janeiro, Campinas, Ribeirão Preto, Belo Horizonte, Brasília, Anápolis, Goiânia e Florianópolis (CARDONA, 2020:8).

2 Para conhecer os dados demográficos sobre os indígenas da Venezuela acesse: http:/ / www.ine.gov.ve

3 Na Venezuela, há uma vasta literatura sobre os Warao, tais como García Castro \& Heinen (1999 e 2000); Heinen (1980) Wilbert (1995 e 1999); García Castro, (2000a e 2000b); Gassón \& Heinen (2012); Suárez (1968); Vaquero Rojo (2000) e González Muñoz (2010).

4 A situação dos Warao na região Norte é abordada por BOTELHO, RAMOS e TARRAGÔ (2017); SONEGHETTI (2017); TARRAGÓ (2017);SANTOS, SONEGUETTI T TARRAGÓ (2018) 
Venho acompanhando essa mobilidade através de diálogo com os Warao e com pesquisadores da região Norte e Nordestes. As informações que tenho acesso, evidenciam que eles têm uma grande agilidade para empreender esses deslocamentos e são muito articulados entre si. As barreiras linguísticas não representam um elemento inibidor para a imigração contínua.

Diariamente, eles trocam informações sobre como estão as condições de abrigamento e os problemas enfrentados nos locais onde estão. Para favorecer ainda mais a comunicação, criaram no dia 09 de maio de 2020, em uma rede social, o grupo Rede Warao Brasil, que está sendo um espaço de intenso diálogos entre eles mesmos e com pesquisadores/as que os apoiam no Brasil. É constante também a comunicação com os parentes que estão na Venezuela, através dos quais ficam sabendo das condições adversas que persistem, impossibilitando a ideia de retorno ao país de origem.

No Brasil, de acordo com a ACNUR (2020), temos 5.043 indígenas venezuelanos. Warao é o grupo mais numeroso com $65 \%$ deste contingente, seguido dos Pemom $(30 \%)^{5}$, Eñepa (3\%) e Kariña (1\%) e Wayúu (1\%). Estão inseridos em um fluxo migratório mais intenso que já alcança cerca de 260 mil venezuelanos ${ }^{6}$ em nosso país.

Quando chegaram à Teresina, os Warao ocuparam uma praça da cidade e passaram a realizar a prática da coleta nas ruas da cidade. Eles se tornaram notícia frequente nos meios de comunicação, que incialmente os tratava genericamente como "os venezuelanos". Integrantes do Movimento Pela Praz na Periferia (MP3), sensibilizados com a vulnerabilidade do grupo, orientaram o deslocamento para a sede do Clube Social Piratinga, no bairro Poti Velho. A Pastoral do Povo de Rua, a Ong Eu Quero Ajudar e a Cáritas da Arquidiocese de Teresina passaram a contribuir com a doação de alimentos égua.

Nas semanas seguintes, novos grupos chegaram, tornando necessário a busca de novos espaços de abrigamento. O abrigo do Poti Velho foi o primeiro espaço que visitei. No local conheci Lucineide e Luciana ${ }^{7}$, que me guiaram até uma casa no bairro Mocambinho, onde estavam algumas famílias que haviam chegado recentemente. $\mathrm{O}$ abrigamento nesta residência aconteceu graças a mediação de padre João Paulo, da Pastoral do Povo de Rua. Neste dia fiquei muito preocupada com a vulnerabilidade das famílias e a precariedade e falta de segurança dos dois espaços.

O grupo que estava no Mocambinho era constituído de mulheres e crianças. Posteriormente, fiquei sabendo que esta é era uma estratégia adotadas nos deslocamentos dos Warao. As mulheres chegam primeiro com as crianças e passam a pedir nas ruas da cidade, pois há uma maior sensibilidade da população com as mulheres com crianças e isso resulta em um número maior de doações. Assim que elas conseguem arrecadar uma certa quantia, custeiam o deslocamento dos homens do grupo. O método adotado é recriminado por algumas pessoas, que advertem que as mulheres e as crianças são mais suscetíveis à violência urbana. Essa narrativa foi sustentada, por exemplo, quando o grupo foi obrigado a deixar casa do referido bairro devido ao medo de serem atacadas por ladrões no meio da noite. Uma vez que elas passavam o dia coletando nas ruas, à noite ficavam na casa com o dinheiro que haviam arrecadado e isso passou a atrair a atenção de elementos mal intencionados que tentaram invadir a residência.

5 A ACNUR cita os Pemon como refugiados, mas para alguns eles são indígenas transfronteiriços. Andrello (1993) afirma que eles habitam a região da tríplice fronteira: Brasil, Venezuela e Guiana. Essa denominação étnica é uma auto-designação dos Arekuna, Kamarakoto, Taurepang e Macuxi.

6 De acordo com a ACNUR (2020), os refugiados venezuelanos foram realocados em mais de 450 municípios de 25 estados brasileiros. Cerca de 70\% deste contingente foi realocado em São Paulo, Amazonas, Santa Catarina, Rio Grande do Sul e Paraná. Os venezuelanos foram realocados em todo o país para mais de 450 municípios em 25 das 27 unidades federais do Brasil. A maioria das realocações está agrupada em cinco estados: São Paulo, Amazonas, Santa Catarina, Rio Grande do Sul e Paraná. Combinados, esses estados estão hospedando mais de $70 \%$ da população total realocada.

7 Membros da Cáritas Arquidiocesana de Teresina que acompanham os Warao desde que chegaram a capital piauiense. 
A presença dos Warao sensibilizou muitas pessoas em Teresina e no início, eles informam que receberam muitas doações, porém alguns itens não eram considerados apropriados para o uso e consumo. Como eles não se apegam ao que não consideram útil de acordo com suas práticas culturais, houve muitas reclamações quando foi constatado o descarte de objetos e alimentos recebidos.

No intuito de prestar assistência, alguns agentes de movimentos sociais, das pastorais e do poder público municipal e estadual passaram a dialogar com eles e entre si. Reuniões foram realizadas para refletir sobre a situação e o Ministério da Cidadania e a Agência da ONU para Refugiados (ACNUR) no Brasil foram acionados, pois ganhou evidencia a identidade de imigrantes refugiados. Em decorrências do diálogo entres as organizações governamentais e não governamentais, criou-se uma rede de parceria para ajudar essa coletividade. As redes sociais, especificamente o whatsapp, passaram a ser utilizadas para a comunicação de um grupo que se constituiu com a denominação de Coordenação Geral.

Provocada pelo MP3, a juíza da $1^{\text {a }}$ Vara da Infância e Juventude de Teresina, realizou audiência pública no dia 31 de maio de 2019 para debater a situação dos Warao. Nesta ocasião estava sendo bastante problematizado a presença de mulheres adultas e idosas com criança fazendo a coleta nas ruas da cidade, ato definido como mendicância. Indesejável, essa prática passou a ser evocada como uma violação ao Estatuto do Idoso e da Criança e do Adolescente.

Neste aspecto, vale mencionar a percepção de alguns Warao sobre essa ação. Ao chegar nos abrigos, por diversas vezes quando perguntei por alguém que não estava no local, eles respondiam que a pessoa estava trabalhando. Um dia, no abrigo do Poti Velho, quando perguntei por Abel e Rafael, disseram-me que eles tinham viajado para trabalhar. Posteriormente, soube que eles estavam em Caxias (MA), haviam alugado uma casa e estavam pedindo nas ruas da cidade.

Da referida audiência participaram conselheiros tutelares, representante do MP3, da Secretaria Estadual da Assistência Social (SASC), da Secretaria Municipal de Cidadania, Assistência Social e Políticas Integradas (SEMCASPI), Secretaria de Educação (SEMEC), Defesa Civil e Cáritas da Arquidiocesana de Teresina. A situação das crianças e as condições precárias das habitações ocupadas pelos Warao foram bastante debatidas e, ao final, a juíza solicitou algumas providências. De acordo com o Termo da Audiência, foi dado um prazo de cinco dias para a SASC, SEMCASPI, Fundação Municipal de Saúde e Defesa Civil comunicarem as ações desenvolvidas e as que iriam desenvolver para atender os Warao abrigados, neste momento, nos bairros Poti Velho, Mocambinho eSanto Antônio / Km 7. Solicitou a elaboração de um protocolo para a conscientização dos indígenas sobre a cultura brasileira, com a orientação de que evitassem a mendicância nos sinais da cidade com crianças e adolescentes. Pediu que fosse notificada a assessoria de imprensa do Estado e do Município, para que conscientizassem a população quanto a presença dos venezuelanos na cidade e para aceitação destes como estrangeiros refugiados em situação de vulnerabilidade.

Para a efetivação da assistência aos Warao, o Governo do Estado do Piauí e a Prefeitura de Teresina fizeram uma pactuação. O primeiro ficou responsável pela cessão de prédios públicos para o abrigamento e o segundo por fornecer alimentação e material de limpeza e higiene pessoal. Mesmo com a referida atribuição de responsabilidades, continuou sendo necessária as doações, pois sempre que visitávamos os abrigos, eram recorrentes as falas sobre a falta de alimentos e outros recursos. As instituições do estado e município, quando interpeladas, verbalizavam que o motivo principal para o atendimento precário era a falta de recurso. 


\section{Estruturação das ações de acolhimento}

Nos primeiros meses, considerando a vulnerabilidade dos Warao, foram desenvolvidas ações emergenciais que contemplaram campanha de doação de alimentos, roupas, produtos de limpeza e higiene pessoal. Apesar de algumas manifestações de solidariedade, passamos a verificar o declínio das doações devido a circulação de uma mensagem nas redes sociais de uma pessoa não identificada, que afirmava que a prefeitura estava suprindo todas as necessidades dos Warao e que não devia ser feita nenhuma doação para eles por esse motivo. Diante da intensa carência que persistia, em parceira com o Instituto Federal do Piauí (IFPI), Cáritas, Funai e AEFAPI, iniciamos no mês de julho de 2019 uma campanha de doação de alimentos e materiais de limpeza e higiene pessoal. Para orientar os donativos e evitar o desperdício, optamos por listar os itens que deveriam ser doados, observando a especificidade da cultura Warao ${ }^{8}$. Apesar da credibilidade das instituições envolvidas na campanha, persistiu a dificuldade nas doações.

$\mathrm{Na}$ medida em que passamos a dialogar mais intensamente com os Warao, tornou-se evidente que a situação em que eles se encontravam demandava ações e reflexões mais elaboradas, em vista de favorecer a inclusão e o respeito aos direitos que possuem. Contudo, quando passamos a sustentar essa ideia publicamente, houve algumas resistências, pois neste momento estava sendo dito por alguns agentes do poder municipal que a presença dos Warao era temporária; afirmavam que eles eram nômades e estavam em Teresina de passagem. No dia 22 de junho de 2019, quando alguns se ausentaram, chegou a ser noticiado que eles tinham iniciados o processo de saída da cidade ${ }^{9}$. Durante uma reunião, fiquei sabendo que a intenção da prefeitura era estruturar ações para um período de seis meses, pois essa era a expectativa de tempo máximo de permanência deles na capital piauiense.

Com o passar dos dias ficou difícil sustentar a tese de nomadismos, pois eles continuavam em Teresina e novas famílias chegavam, principalmente de Belém (PA) e São Luís (MA). Como foi dito, em julho de 2019, dois meses após a chegada das primeiras famílias, o contingente populacional já havia atingido cerca 200 indígenas.

Nas visitas aos abrigos que continuei realizando, verifiquei que havia deslocamentos de alguns para São Luís, Caxias e Fortaleza; mas sempre seguido de um retorno, em alguns casos. Uma das razões para essas viagens, segundo eles, era o declínio das manifestações de solidariedade da população local. Nos abrigos, os recursos destinados pelo poder público contemplavam de forma insuficiente a alimentação e material de limpeza. Eles afirmavam que necessitavam de itens como leite e fralda para as crianças e materiais de higiene pessoal. $\mathrm{O}$ dinheiro que coletavam nas ruas era utilizado para prover essas carências, para viabilizar o deslocamento de outros Warao e ajudar financeiramente os parentes que estavam passando por dificuldades em outras cidades brasileiras e, até mesmo, venezuelanas.

Em São Luís, constitui-se um núcleo de Warao $^{10}$, em Caxias não consegui saber se alguém permaneceu e em Fortaleza não houve condições de se fixarem. Conversei com algumas mulheres do abrigo CSU do Buenos Aires, que me disseram que não gostaram do período que ficaram nesta cidade. Elas alugaram um quarto nas proximidades da rodoviária, durante o dia saiam para pedir e todos as noites, quando chegavam à pensão, o proprietário cobrava a diária da hospedagem e não aceitava que elas preparassem alimentos dentro das instalações. Uma delas ficou doente e resolveram retornar para Teresina. Avaliaram que era a melhor saída, pois aqui tinha o abrigo, onde estavam os parentes e não precisavam pagar para ficar no local; recebiam alimentos da prefeitura e podiam cozinhar.

Desde que conheci os Warao, tenho escutado inúmeros relatos sobre os familiares que estavam em outros locais acometidos por doença e falta de alimentos. Certa vez, Yovini Torres

\footnotetext{
8 Para conhecer a campanha ver: https://ufpi.br/ultimas-noticias-ufpi/32125-ufpi-e-ifpi-realizam-campanhade-solidariedade-aos-indigenas-warao

9 https://www.meionorte.com/noticias/venezuelanos-comecam-a-deixar-teresina-365583

10 Algumas famílias que chagaram em Teresina dizem que passaram um tempo em São Luís (MA).
}

EntreRios - Revista do PPGANT -UFPI -Teresina •Vol. 3, n. 2 (2020) 
compartilhou o seu sofrimento, pois havia escutado de um funcionário da Prefeitura que não receberiam mais indígenas nos abrigos, devido à insuficiência de recursos do poder municipal. Ele confidenciou que entendia as limitações do poder municipal, mas para ele era muito difícil recusar a vinda dos parentes que estavam em Boa Vista (RR) sofrendo com a superlotação nos abrigos desta cidade. Ele mesmo havia morado na capital roraimense e foi obrigado a partir, pois era insustentável a permanência no local.

Depois de falar dos inúmeros problemas enfrentados pelo seu povo na referida cidade, mencionou que além dos Warao, há um contingente ainda maior de criollos (venezuelanos não indígenas) e haitianos, o que agrava ainda mais a situação dos refugiados.

Yovini é o Warao com quem mais mantenho diálogo. Ele é muito inteligente e sensível. Era professor na Venezuela, domina bem português e tem se tornado uma referência na cidade. Todas as instituições o procuram quando precisam dialogar com os Warao. Devido a liderança que possui, quando chegou o recurso do governo federal ${ }^{11}$ para a gestão dos abrigos, ele foi contratado como supervisor ${ }^{12}$.

Apesar das dificuldades enfrentadas em Teresina, os Warao manifestam a intensão de permanecer na cidade. Como mencionei, o conhecimento desta pretensão evidenciou a necessidade de pensarmos novas ações de acolhimento. Com essa pretensão, realizamos o Seminário Indígenas Warao: Direitos e Práticas de Acolhimento e Proteção, nos dias 10 e 13 de setembro de 2019, no Centro de Ciências Humanas e Letras da Universidade Federal do Piauí. O evento foi bastante produtivo e contou com uma rede de parcerias que agregou a Universidade Federal do Piauí (UFPI) ${ }^{13}$; Fundação Nacional do Índio (Funai); Alto Comissariado das Nações Unidas para os(as) Refugiados(as) (ACNUR/ONU); Defensoria Pública da União (DPU); Articulação dos Povos e Organizações Indígenas do Nordeste, Minas Gerais e Espírito Santo (APOINME); Instituto Federal do Piauí/Núcleo de Estudos Afro-Brasileiros e Indígenas (NEABI); Secretaria de Estado da Assistência Social, Trabalho e Direitos Humanos (SASC); Superintendência das Relações Sociais do Governo do Estado do Piauí (SUPRES); Secretaria Municipal de Cidadania, Assistência Social e Políticas Integradas da Prefeitura de Teresina (SEMCASPI); Núcleo de Direitos Humanos da Defensoria Pública do Estado do Piauí e Cáritas Arquidiocesana de Teresina.

Construída em diálogo com os Warao e as organizações parceiras, a programação foi constituída de conferência, mesas redondas, minicurso, palestra, grupo de discussão e exposição de artesanatos produzidos pelos(as) indígenas. Participaram do seminário 337 pessoas, sendo 80 Warao (adultos(as) e crianças). Entre os inscritos, identificamos integrantes da comunidade universitária, organizações governamentais, pastorais, movimentos sociais e outros segmentos da sociedade civil. Considerando o pouco conhecimento que tínhamos sobre o grupo, convidamos as pesquisadoras venezuelanas Rosa Elizabeth Acevedo Marin (UFPA) e Jenny González Muñoz (UFMG), que conhecem os Warao há décadas. Elas nos ajudaram bastante a entender criticamente a situação dos indígenas na Venezuela e a cosmologia Warao.

Em síntese, foram dias de intensa reflexão e debate sobre a situação dos Warao em Teresina. Bastante oportuno foi o despontar da concepção de que eles são portadores de direitos em nosso país enquanto indígenas, imigrantes e refugiados. A programação foi direcionada a

11 Apenas no final do ano de 2019, a Prefeitura de Teresina recebeu recurso do governo Federal para manter os abrigos.

12 Recentemente, fiquei sabendo que Yovini deixou de receber salário desde agosto de 2020 e que a Fundação Cajuína informou que o motivo da suspensão do contrato foi a falta de recursos. Isso foi gerou descontentamento, pois alguns Warao questionaram a demissão dele e a manutenção dos contratos de outros funcionários não indígenas. A notícia de contratação de agentes de portaria para o turno noturno aumentou o aborrecimento. Eles alegam que as contratações anunciadas evidenciam o desejo da Prefeitura de vigiá-los até a noite e destacam que a atuação de Yovini e educadores sociais deveria ser uma prioridade, para minimizar a ociosidade nos abrigos.

13 Trabalharam na realização do seminário docentes e discentes das seguintes áreas: Laboratório do Projeto Nova Cartografia Social da Amazônia, Programa de Pós-Graduação em Antropologia, Departamento de Ciências Sociais (DCIES), Departamento de Serviço Social (DSS), Programa de Pós-Graduação em Políticas Públicas (PPGPP), 
esse fim e a atuação da FUNAI, ACNUR, DPE e DPU ajudaram bastante neste entendimento. Isso pode parecer aos leitores algo muito evidente, mas foi uma percepção que alterou o discurso de alguns participantes, que equivocadamente acreditavam, por exemplo, que os Warao obrigatoriamente deviam se enquadrar aos nossos padrões culturais e caso isso não acontecesse, poderiam ser mandados de volta para o pais de origem. Igualmente danosa, era a afirmação de que "eles são um problema da Venezuela e não do Brasil; o justo é cuidarmos dos nossos indígenas e pobres, que são muitos, e não dos venezuelanos". E para finalizar, "quanto mais ajudarmos, mais o problema vai aumentar, pois motivará a vinda de outros Warao para o Piauí". Essas afirmações, que ainda persistem, são um grande entrave para a construção de relações interculturais.

A final do seminário, foi construído o documento Propostas de Acolhimento e Proteção ao Povo Warao, que contém ações emergenciais, em curto, médio e longo prazo, que tem a finalidade nortear a atuação dos entes públicos municipais, estaduais e federais e a sociedade civil brasileira. Neste documentos as ações são elencadas a partir dos seguintes aspectos: temporalidade, demanda, providências (o que fazer?), meios necessários (como fazer) e os responsáveis, A proposta é inclusiva e visa o compromisso com a concretização dos direitos dos Warao, a cooperação entre os povos, o combate ao racismo e à xenofobia; o respeito à diversidade e a promoção da dignidade humana.

Nesta construção, que considero uma demonstração de que a interculturalidade é possível, o protagonismo dos Warao foi surpreendente. Em seus próprios termos, participaram ativamente das atividades e se apropriaram do seminário de acordo com os seus interesses e necessidades. Eles aproveitaram a ocasião para apresentar as suas demandas e mostraram a existência de uma organização social e política bem articulada entre os núcleos familiares que vivem nos abrigos. Por iniciativa própria, chamaram o líder Aníbal Perez Cardona, que veio de São Luís (MA) com a finalidade exclusiva de participar do seminário. Além deste, pela atuação política no uso da palavra, destacaram-se Yovini, Guerrero, Abel, Rafael, Maritza e Yumeli. Foi recorrente os pedidos de ajuda pautados em uma consciência política admirável. Evidenciaram o desejo de apreender o português e pediram a oportunidade de trabalho para poderem viver com um pouco de dignidade no Brasil.

Dando continuidade as atividades desenvolvidas com os Warao, o Núcleo de Direitos Humanos e Tutela Coletiva da Defensoria Pública do Estado do Piauí realizou uma reunião no dia 23 de outubro de 2019, com a finalidade de apresentar as propostas do seminário e constituir o Grupo de Trabalho (GT) para monitorar as políticas públicas desenvolvidas com os Warao. Integro o referido grupo, que conta com a participação de representantes da Prefeitura de Teresina, Governo do Estado, Defensoria Pública do Estado, Defensoria Pública da União, a FUNAI, CÁRITAS e ACNUR.

Um ano após a efetivação do seminário, é possível afirmar que alguns passos foram dados, contudo a maioria das propostas presentes nas 23 páginas do documento produzido no seminário ainda precisam ser efetivadas. O próprio GT teve dificuldade de realizar reuniões periódicas, mas recentemente as atividades foram retomadas, reanimando a esperança de avançar na proposta de relações interculturais com os Warao. Contudo, percebo que a pandemia impactou as pessoas e as organizações impossibilitando a realização de atividades, representando um desafio ainda não superado.

Avaliando a trajetória dos Warao em Teresina, vejo com preocupação a dificuldade de incluí-los no processo de idealização e efetivação das ações desenvolvidas. Outro problema grave é falta de atenção à autonomia indígena. Para construir diálogos interculturais será necessário o abandono da prática de decisões verticalizadas e a visão etnocêntrica que prevalece no assistencialismo que vem sendo praticado.

Departamento de Ciências Jurídicas (DCJ), Centro Acadêmico de Ciências Sociais (CACS), Núcleo de Estudos em Saúde Pública (NESP), Coordenação de Letras Estrangeiras - Português e Grupo de Estudos e Pesquisas sobre Identidades Coletivas, Conhecimentos Tradicionais e Processos de Territorialização. 
Abordarei a partir de agora alguns casos exemplares para comunicar minha percepção das situações vivenciadas, mostrando os avanços e impasse para a efetivação da interculturalidade, que deve ser o princípio norteador de relações inclusivas. Posições etnocêntricas constituem um fator que favorece a vulnerabilidade dos Warao, afeta a sua dignidade e os coloca em uma posição de submissão e exclusão.

\section{Tensões e conflitos no acolhimento aos Warao}

O primeiro episódio que abordarei refere-se ao remanejamento dos indígenas para o prédio do CSU Buenos Aires. Na pactuação firmada para a assistência aos Warao, como foi dito, coube ao governo do Estado a responsabilidade de disponibilizar imóveis para o abrigamento. De acordo com essa atribuição, foi realizada a reforma do prédio onde funcionava um Centro Social Urbano (CSU), contudo o remanejamento das famílias gerou muita tensão, pois no dia da mudança para o local ganhou visibilidade a falta de entendimento dos indígenas em relação à proposta de ocupação do novo espaço. As divergências entre os núcleos familiares eclodiram, resultando na recusa de compartilhar o mesmo espaço.

No dia, antes de chegar ao CSU do Buenos Aires, recebi uma ligação da superintendente da SUPRES pedindo ajuda, pois a confusão que se formou estava difícil de administrar. Chegando ao local, de fato a situação era caótica. Os indígenas estavam irritados, falavam entre sim em warao e ninguém os entendia. As famílias lideradas por Guerrero chegaram primeiro ao local e ocuparam todos os quartos, que eram insuficientes até mesmo para eles. O grupo liderado por Celso, vendo a situação, ser recusou a entrar. Ficaram do lado de fora do prédio e como não foi apresentada nenhuma outra possibilidade, eles prefeririam ir embora neste mesmo dia para São Luís (MA). Fiquei sabendo que o grupo liderado por Abel e Rafael, anteriormente, não havia aceitado a ida para o novo espaço, mesmo sabendo que o prédio em que moravam estava comprometido e a instalação elétrica representava um sério riscos aos ocupantes.

Neste dia, verbalmente, recebi o pedido de ajuda de funcionário/as da SUPRES, SEMCASP $^{14}$ e do administrador do abrigo, que havia sido contratado recentemente pela prefeitura. Afirmaram que em seus quadros de funcionário não havia pessoas preparadas para lidar com os Warao e que precisavam da ajuda da universidade e da minha contribuição como antropóloga. Para minimizar a expectativa acerca da Antropologia, expliquei que trabalhava com povos indígenas, mas não conhecia os Warao; que os povos indígenas são diversos e isso deviria ser levado em consideração.

A confusão que se criou certamente foi determinante para o pedido de ajuda e com o passar dos dias. Contudo, foi a relação estabelecida com os Warao que mais me motivou para escrever a proposta do seminário. Passamos a trabalhar no projeto do seminário, que foi devidamente cadastrado como evento de extensão na UFPI. A longo desse processo foram sendo construídas as parcerias com as instituições mencionadas anteriormente e, principalmente, o diálogo com os Warao, pois a nossa preocupação maior era contar não apenas com a anuência do grupo, mas incluí-los efetivamente na atividade. Observando o princípio da interculturalidade, o seminário não poderia ser apenas um momento de reflexão sobre eles como destinatários das ações, era preciso refletir com eles, considerando a necessidade de respeito à identidade, à cultura e à autonomia indígena.

14 Em relação a SEMCASPI, quando chegou o recurso do governo federal, que contemplava a contratação de pessoas para trabalhar nos abrigos, solicitaram ajuda novamente. Desta vez apresentaram a solicitação de um curso de formação para os/as contratados. O curso de extensão ASSISTÊNCIA E INCLUSÃO DOS INDÍGENAS WARAO chegou a ser cadastrado na Pró-Reitoria de Extensão e Cultura da UFPI, mas não ocorreu devido a um conflito que emergiu. Ele estava estruturado na abordagem dos seguintes temas: 1) Cultura e identidade indígena; 2) Direitos Indígenas e Política Indigenista no Brasil; 3)Os indígenas Warao: cultura, identidade e trajetória; 4 ) O acolhimento e a proteção de refugiados e 5) Acolhimento e proteção dos Warao em Teresina: experiências, desafios e perspectivas.

EntreRios - Revista do PPGANT -UFPI -Teresina • Vol. 3, n. 2 (2020) 
Neste momento havia apenas dois abrigos localizados nos bairros Poti Velho e Buenos Aires. No período que antecedeu o seminário, passamos a visitar mais intensamente o CSU do Buenos Aires, pois a Cáritas atuava intensamente no outro abrigo e assumiu a responsabilidade da articulação necessária neste espaço.

$\mathrm{Na}$ medida em que perceberam que estavam sendo valorizados, os Warao passaram a apresentar as suas demandas. Pediram materiais para confeccionar artesanatos, para expor e vender durante o seminário. Solicitaram tecido para confeccionar as roupas tradicionais, pois desejavam cantar e dançar, para mostrar a beleza de sua cultura. Elaboramos o cardápio da alimentação de acordo com as preferencias alimentares juntamente com a Cáritas, que complementou os gêneros alimentícios doados pela prefeitura. A FAPEPI e o Governo do Estado contribuíram no financiamento das despesas do evento e as instituições parceiras assumiram os custos de deslocamento e hospedagem de seu funcionário. A FUNAI enviou uma delegação ${ }^{15}$ e trabalhou intensamente em todas as atividades.

Inicialmente, pensamos que seria possível apenas a participação dos aidamos (dirigentes Warao) de cada abrigo e alguns representantes dos núcleos familiares devido aos poucos recursos. Na medida em que eles se apropriaram da proposta do seminário, esse número foi aumentando. No auge do entusiasmo, eles manifestaram o desejo de que todos participassem, mas argumentamos que não teríamos estrutura para assegurar o bem estar e a participação de todos/as. Falamos da questão da língua, pois era necessário assegurar que eles entendessem o que estava sendo dito e que o público presente também compreendesse o que eles falassem. Avisamos que estávamos providenciando uma equipe de alunos da $\mathrm{UFPI}^{16}$ para atuarem como intérpretes, mas eram poucos alunos. Negociamos e ao final encontramos um meio termo entre a demandas dos Warao e as nossas possibilidades. O resultado foi a participação de 80 indígenas Warao.

Quando tudo pareceria bem encaminhado surgiu um impasse. Os dois grupos não aceitaram compartilhar o mesmo espaço e neste momento a cosmologia religiosa do grupo se evidenciou como o motivo da recusa. A comissão organizadora afirmou que não era possível realizar dois seminários, principalmente devido à falta de recursos e a disponibilidade das pessoas envolvidas. Para superar esse obstáculo foi necessário considerar as razões por eles apresentadas e negociar uma saída que fosse minimamente satisfatória.

A recusa de compartilhar o mesmo espaço foi mencionada primeiramente no abrigo do bairro Poti Velho, liderado neste momento por Abel e Rafael. Em síntese, eles disseram que estavam sem proteção espiritual, pois a senhora que rezava e curava os acometidos de feitiço estava em São Luís. Eles sabiam que no outro abrigo tinha um chamán (wisi-datu) ${ }^{17}$, que estaria pronto para realizar os rituais de cura e para proteger o seu grupo, caso fosse necessário.

Dias antes, eu havia escutado o relado de uma integrante da Cáritas sobre uma pessoa doente no abrigo do Poti Velho. A pessoa enferma transpirava excessivamente e tremia, mas eles recusavam a possibilidade de levar a pessoa para o hospital, pois aguardavam a chegada de uma senhora do grupo que estava fazendo a coleta nas ruas da cidade. Essa situação deixou a integrante da Cáritas muito aflita e sem saber ao certo como agir. Enquanto dialogava com os presentes, insistindo em levar a pessoa para o hospital, chegou à senhora que estava sendo esperada. A pessoa enferma foi colocada em uma cadeira, a senhora se aproximou e começou a pronunciar algumas palavras, que em alguns momentos se assemelhavam a um canto de melodia bastante lenta. A pessoa parou de transpirar, parou de tremer e se acalmou. Desta forma, foi resolvido o problema.

15 Da Coordenação Regional Nordeste II participaram Renata Catarina Costa Maia, Clarissa N. M. Tavares e Sérgio Paulo Azevedo dos Santos. Da Funai de Brasília vieram Ruth Emanuelle do N. Sampaio, Léia do Vale Rodrigues e Ivanise R. dos Santos.

16 Para exercer a função de intérpretes foi constituída uma equipe com alunos da UFPI originários de país de língua espanhola.

17 Indígenas portador de poderes sobrenaturais que cura as enfermidades.

EntreRios - Revista do PPGANT -UFPI -Teresina •Vol. 3, n. 2 (2020) 
Durante a negociação para a realização do seminário, fiquei sabendo que a pessoa enferma mencionada no episódio havia encontrado nas ruas da cidade com uma determinada pessoa do outro abrigo, que lhe colocou um jebu do mal (espírito do mal). Nos dias que antecederam o seminário, a senhora que curou o enfermo havia viajado para São Luís, por esta razão estavam desprotegidos espiritualmente e temiam compartilhar o mesmo espaço que os outros.

De fato, este receio foi constatado em maior intensidade entre os indígenas do abrigo do Poti Velho. Quando mencionamos a possibilidade de um acordo entre os grupos, a fim de que ninguém colocasse jebu do mal (espírito do mal) durante o seminário, as lideranças do CSU do Buenos Aires se dispuseram a ir ao Poti Velho para negociar o acordo. Caso recusassem essa proposta, eles estavam dispostos a recebê-los. Quando apresentamos a proposta, foi prontamente recusada, pois acreditavam que corriam risco das duas formas. Refletiram e apresentaram uma contraproposta: o encontro deveria ser entre as lideranças em um local neutro. Aproveitamos, então, para propor que a conversa fosse realizada na UFPI, assim eles também conheceriam o local de realização do seminário. Essa proposta foi aceita por todos.

O encontro aconteceu na manhã do dia 02 de setembro de 2019, na sala do Laboratório do Projeto Nova Cartografia Social da Amazônia, no Centro de Ciência Humanas e Letras da UFPI. Nesta ocasião estavam presentes representantes das organizações que integravam a comissão organizadora do evento, o Defensor Público Estadual e o administrador do abrigo. Assim que eles chegaram, iniciamos com uma breve explanação sobre o objetivo da reunião. Em seguida, eles pediram para conversar separadamente, o que fizeram na língua indígena. Não sabemos o que foi dito, mas ao final, Yovini nos informou que haviam assumido o compromisso de compartilharem o mesmo espaço e não colocarem jebu do mal em nenhuma pessoa durante a realização do seminário, desta forma ninguém ficaria enfermo.

Figura 1 e 2: Reunião realizada no dia 02 de setembro de 2029, ocasião em que celebraram o acordo de compartilhamento do mesmo espaço

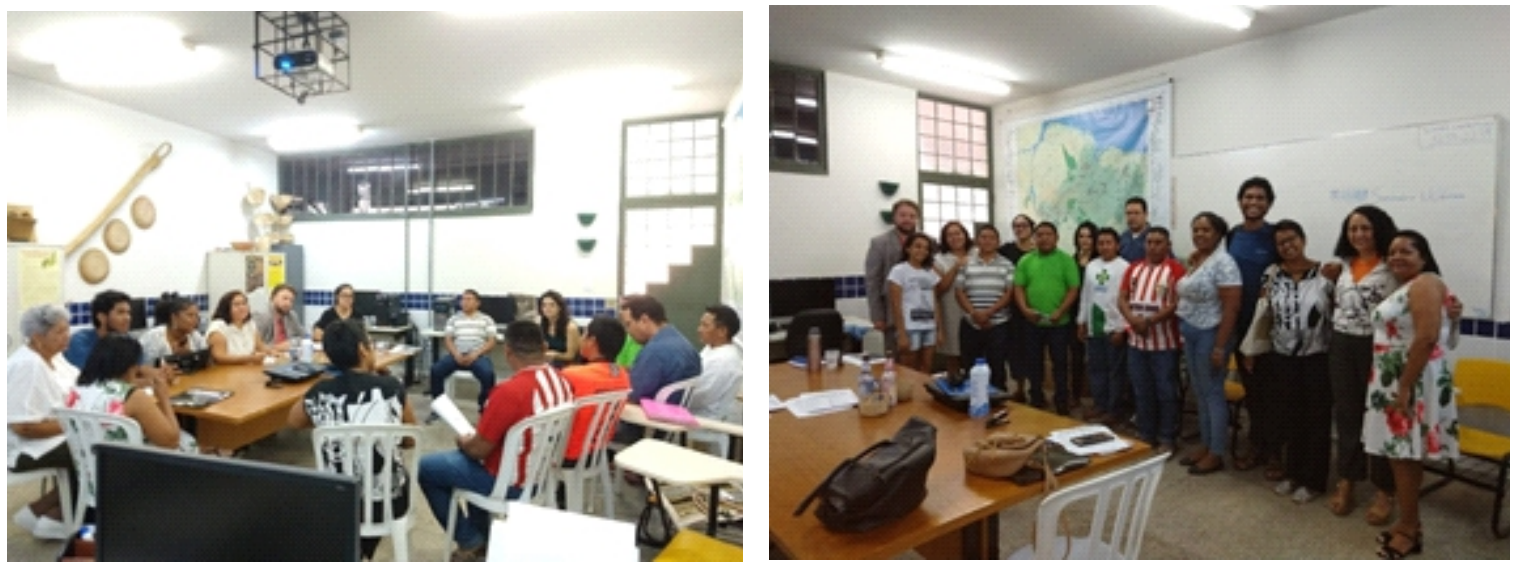

Fonte: Autora

A partir dessa descrição desejo evidenciar a importância do diálogo, do respeito e a capacidade de negociar com os Warao. Sem perder de vista os nossos objetivos e possibilidades, consideramos a posição deles e respeitamos os saberes que possuem. As crenças indígenas não foram tratadas como coisa sem importância. O diálogo intercultural que produz resultados mais satisfatórios deve ser pautado no respeito mútuo, dever partir do reconhecimento dos saberes diversos e levar ao respeito de todos os envolvidos.

Descreverei agora outro episódio, o remanejamento de parte dos Warao do abrigo Buenos Aires, para mostrar as tensões que se evidenciam quando não há o reconhecimento dos saberes diversos e nem reconhecimento da autonomia dos indígenas. Nesse caso a assimetria de poder ganha peso, resultando na imposição da vontade de uma das partes. 
No contexto da pandemia, foi proposto o deslocamento de 60 indígenas do CSU do Buenos Aires para a sede da EMATER, localizada na Br 343, na saída da cidade. O deslocamento de parte do grupo foi adotado como forma de reduzir a aglomeração no abrigo do CSU do Buenos Aires, que no momento contava com 141 indígenas. Dois dias antes da data marcada, passamos a receber ligações dos indígenas informando que eram contrários a divisão do grupo e, principalmente, aos critérios adotados pela administração do abrigo para definir os que ficariam e os que seriam levados para o novo espaço.

Inicialmente, refletimos sobre os riscos de aglomerações no contexto da pandemia, tentando mostrar a eles que essa era uma boa opção no momento. Orientamos os indígenas a tentarem dialogar com a equipe da Prefeitura, para explicar as razões da recusa e tentar negociar novos critérios para a definição dos que seriam remanejados. Eles estavam bastante exaltados diante da ideia de separação entre parentes muito próximos de uma mesma família. As ligações se intensificaram, desta vez nos informando que a coordenadora do abrigo se recusava a escutálos e que havia dito que os que não acatassem a determinação teriam que abandonar o local.

Assim que se iniciaram as ligações informando o conflito, postei a ocorrência no grupo de whatsapp Coordenação Geral, que conta com a participação de funcionários da SEMCASPI/Prefeitura de Teresina. Em resposta, uma funcionária confirmou que eles seriam remanejados, que haviam visitado a EMATER e que tinham gostado do espaço. Não foi considerada a argumentação dos indígenas e a ameaça de expulsão do abrigo.

Na noite anterior ao dia do remanejamento, as ligações aumentaram e desta vez foram acompanhadas do pedido da nossa presença. Eles ressaltaram que alguns iriam se recusar a sair do abrigo do Buenos Aires e tinham medo de serem expulsos. Diante do quadro, fomos obrigadas a responder a solicitação por eles apresentada. No horário indicado pelos Warao, fui ao abrigo, juntamente com Raquel Barros, uma amiga voluntária que mora nas imediações do CSU, Lucineide e Luciana, que são da Cáritas.

O momento foi bastante tenso. Fomos convidadas pela coordenadora a sair do abrigo com a alegação de que não nos conhecia. Tentamos nos apresentar e informar que fazíamos parte do Grupo de Trabalho Interinstitucional que havia sido criado após a realização do seminário para acompanhas as ações com os Warao. A tensão aumentou quando eles perceberam a chegada de uma viatura da Guarda Municipal e logo em seguida a equipe de uma tv local. Continuamos tentando dialogar, apresentamos as razoes mencionadas pelos indígenas e perguntamos se não haveria a possibilidade de negociar os critérios de definição de quem deveria ir para a EMATER. A exaltação do momento dificultou o diálogo e a coordenadora do abrigo dizia que havia sido feito um estudo e que tinha sido constatado que havia três grupos distintos no abrigo e que ela tinha se baseado nesta constatação para fazer a lista com os nomes de quem seria remanejado. Os indígenas já tinham me informado sobre essa narrativa e esclareceram que houve uma compreensão equivocada. Para facilitar a execução das atividades dentro do abrigo, eles se subdividiram em três equipes e quando informaram essa organização, entenderam que eram três grupos diferentes.

Algumas pessoas que estavam se opondo ao remanejamento recusavam a separação de parentes muito próximos. Citaram com exemplo uma indígena gravida e enferma, que seria separada de seu pai, que é idoso e cego. Ela frequentemente sofria com dores de cabeça, que só eram curadas com a reza do pai. O cacique deveria ir para o novo abrigo, mas sua mãe deveria ficar. Existia, ainda, certas contradições: indígenas que estavam na lista, não queriam ir; por outro lado, havia indígenas que desejavam, mas não podiam por não ter o nome na lista. Por diversas vezes tentamos explicar tudo isso, mas o conflito que se instalou não favoreceu ao entendimento dos motivos elencados. A possibilidade de diálogo se extinguiu quando pergun-

18 Grupo criado para manter o diálogo entre as instituições que desenvolvem ações com os Warao.

19 Quando os Warao chegaram em Teresina o termo aidamo era bastante utilizado, no contexto do conflito percebi uma mudança: o termo cacique passou a substituir o aidamo.

EntreRios - Revista do PPGANT -UFPI -Teresina • Vol. 3, n. 2 (2020) 
-tamos o que aconteceria com os que se recusassem a ir par o outro espaço e a coordenadora do abrigo disse que eles iriam de qualquer jeito.

Como de um lado não havia condições para o diálogo naquele momento, foi necessário negociar com os Warao para evitar um desfecho mais grave. Depois de muita conversa, os que se recusavam aceitaram o remanejamento com a condição de produzirmos um documento, informando as autoridades a ocorrência e apresentando a demanda de todas as famílias permanecerem juntas futuramente. Cumprindo o prometido, no dia 14 de abril de 2020, a DPU recebeu a denúncia através de uma carta assinada pela Caritas da Arquidiocese de Teresina, Pastoral do Migrante, Associação São Paulo Apóstolo - Pastoral do Povo de Rua, Grupo de Pesquisa sobre Identidades Coletivas, Conhecimentos Tradicionais e Processos de Territorialização e Grupo de Pesquisa e Extensão Direitos Humanos e Cidadania - DiHuCi da UFPI.

O registro desta ocorrência foi mencionado no site da prefeitura, situando o deslocamento dos Warao no meio de outras ações voltadas ao enfrentamento da pandemia. O conflito foi negado publicamente.

A coordenação vem realizando esse diálogo há quase duas semanas com eles, tivemos o reforço da antropóloga da unidade explicando a necessidade dos cuidados. Eles aceitaram sem conflitos, contudo tiveram receio em se dividir, pois são três grupos de famílias. Informamos que isso não aconteceria, a divisão foi feita considerando estes laços ${ }^{20}$.

O episódio teve repercussão devido a presença da imprensa. Não sabemos ao certo o efeito da carta de denúncia. A única mudança que tivemos conhecimento foi o deslocamento do pai da indígena grávida, que foi levado para a EMATER para ficar com a sua filha.

\section{Considerações finais}

No momento, a capital piauiense refugia cerca de 208 Warao, que estão abrigados no bairro Poti Velho, Buenos Aires e EMATER/BR 343. O número excessivo de pessoas nestes espaços contribuiu para um alto índice de contaminação com o Coronavírus. Lamentavelmente, houve um óbito e na recente testagem feita pela SESAPI foi registrado que 108 Warao estavam infectados. No contexto da pandemia surgiram algumas tensões devido as crenças religiosas sobre saúde e doença. De acordo com a percepção dos Warao, algumas doenças só podem ser saradas pelos curadores, que praticam procedimentos terapêuticos específicos da medicina indígena. Nestes casos, já houve tensão devido a recusa de levar a pessoa enferma para o posto de saúde. A localização dos wisi-datu do grupo faz necessário o deslocamento entre os abrigos para fazer o diagnóstico da causa da enfermidade, o tipo de tratamento e os rituais de cura necessários. Como o isolamento social é uma orientação das agências oficiais de saúde para conter a pandemia, a mobilidade dos Warao já causou alguns descontentamentos.

O relato etnográfico apresentado mostra o desafio de inserir os princípios da interculturalidade crítica nas ações desenvolvidas com os Warao. O diálogo intercultural, a meu ver, representará o reconhecimento da diversidade como um valor e a possibilidade de construção de relações horizontalizadas e inclusivas. Seguir nessa direção nos levará a cidadania intercultural, enquanto "un régimen de ciudadanía que se basa en las capacidades, intraculturalmente específicas e interculturalmente negociadas, para ejercer los derechos huma-

20 Fala da coordenadora do abrigo citada na notícia postada no site https:/ / pmt.pi.gov.br/2020/04/29/ prefeitura-transfere-grupo-de-venezuelanos-para-novo-espaco/

EntreRios - Revista do PPGANT -UFPI -Teresina • Vol. 3, n. 2 (2020) 
-nos en situaciones donde se presenten desigualdades y asimetrías persistentes e históricamente arraigadas" (DIETZ, 2017: 206). Apostar nas relações interculturais significa acreditar que é possível a convivência e a troca entre culturas distintas, entre Warao e os teresinenses, sem que seja necessário a anulação ou submissão de uma das partes.

\section{Referências Bibliográficas}

ACNUR. Relatório de atividades para população indígena. Agostos de 2020.

AGUILERA URQUIZA e NASCIMENTO. O desafio da interculturalidade na formação de professores indígenas. Espaço Ameríndio, Porto Alegre, v. 4, n. 1, p. 44-60, jan/jun. 2010.

BARTOLOMÉ, Miguel. Procesos interculturales: antropología política del pluralismo cultural en América Latina. México, D.F.:SigloVentiuno Editores, 2006.

BARTOLOMÉ, Miguel Alberto. Las identidades imaginadas: algunos problemas del diálogo intercultural en una sociedad plural. In: MONTARDO, Deise Lucy Oliveira e RUFINO, Márcia Regina Calderipe Farias (Org). Saberes e ciência plural: diálogos e interculturalidade em Antropologia. Florianópolis: Editora da UFSC, 2017.

BELTRÃO, Jane Felipe. Povos indígenas: histórias e histórias sobre políticas afirmativas. In: SOUZA LIMA, Antonio Carlos de Souza, SANTOS, Luis Felipe dos e RIBEIRO, Gustavo Lins (Orgs). Interculturalidade(s): entre ideias, retóricas e práticas em cinco países da América Latina. Rio de Janeiro : Associação Brasileira de Antropologia; Contra Capa, 2018.

BOTELHO, Emília; RAMOS, Luciana; TARRAGÓ, Eduardo. Parecer Técnico $N^{\circ}$ 208/2017/ SEAP $/ 6^{a}$ CCR/PFDC. Ministério Público Federal (MPF), 2017.

CANDAU, Vera Maria; Russo, Kelly. Interculturalidade e educação na América Latina: uma construção plural, original e complexa. In: Revista Diálogo Educacional, vol. 10, núm. 29, janeiroabril, 2010.

CARDONA, Aníbal Perez. Warao tecendo um diálogo de igualdade. S/P: Natal (RN), 2020.

DIETZ, Gunther. Interculturalidad: una aproximación antropológica. Perfiles educativos [online]. 2017, vol.39, n.156.

GARCÍA CASTRO, Álvaro. Mendicidad Indígena: Los warao Urbanos. Boletín Antropológico $n^{\circ}$ 48. Enero-Abril, Centro de Investigaciones Etnológicas - Museo Arqueológico - Universidade de Los Andes. Mérida, 2000a.

.Warao Indian Migrations to Urban Centers in Venezuela: Adaptation as a strategy for survival. Instituto Venezoelano de Investigaciones Científicas (IVIC), Centro de Antropología, Laboratório de Ecología Humana, Caracas, Venezuela, 2000b.

GARCÍA-CASTRO, Álvaro \& HEINEN, Dieter. “Planificando el Desastre Ecológico. El cierre del Caño Manamo en el Delta del Orinoco, Venezuela". In: Antropológica. Caracas: Instituto Caribe de Antropología y Sociología (ICAS). Fundación La Salle. 91,(31-56), 1999.

\& HEINEN, Dieter. Las Cuatro Culturas Warao. In: Tierra Firme. Revista Asbitrada de Historia y Ciencias Sociales. Caracas: No 71. Tercer trimestre, 2000.

EntreRios - Revista do PPGANT -UFPI -Teresina • Vol. 3, n. 2 (2020) 
GONZÁLEZ MUÑOZ, Jenny. La oralidad como instrumento esencial para la reconstrucción de la memoria etnohistórica del pueblo warao. Tesis (Doctorado em Cultura y Arte para América Latina y del Caribe), Instituto Pedagógico de Caracas, Universidad Pedagógica Experimental Libertador, Caracas, 2010.

HEINEN, Dieter. Aportes para una etnografía warao. Caracas: ICAS. Instituto Caribe de Sociología y Antropología, 1980.

QUIJANO, Aníbal. Colonialidade do poder, eurocentrismo e América Latina. In: LANDER, Edgardo. A colonialidade do saber: eurocentrismo e ciências sociais. Perspectivas latino-americanas. CLACSO, Consejo Latinoamericano de Ciencias Sociales, Ciudad Autónoma de Buenos Aires, Argentina, 2005.

MARIN, Rosa Elizabeth Acevedo e JÚNIOR, Amarildo Ferreira. Migrantes, "refugiados venezuelanos": conflitos e políticas de estado. In: REIS, Tiago Siqueira; SOUZA, Carla Monteiro de; OLIVEIRA, Monalisa Pavonne e JÚNIOR, Américo Alves de Lyra (Orgs). Coleção história do tempo presente: volume II. Boa Vista: Editora da UFRR, 2020.

MATO, Daniel (Org). Diversidad cultural e interculturalidad en educación superior. Experiencias en América Latina. Caracas: IESALC-UNESCO, 2008.

NASCIMENTO, Raimundo Nonato Ferreira do. Antropologia, Interculturalidade e Educação Escolar Indígena em Roraima. Curitiba: Appris, 2017.

; QUADROS, Marion Teodósio de e FIALHO, Vânia. Interculturalidade Enquanto Prática na Educação Escolar Indígena. In: Revista ANTHROPOLÓGICAS, Ano 20, 27(1):187-217, 2016.

ROMERO, Carlos Giménez. Interculturalidade e Mediação. Lisboa: Alto Comissariado para a Imigração e Diálogo Intercultural, 2010.

SANTOS, Marcio; SONEGHETTI, Pedro Moutinho Costa; TARRAGÓ, Eduardo. Parecer Técnico No 328/2018-DPA/SPPEA/PGR. Ministério Público Federal (MPF), 2018.

SONEGHETTI, Pedro Moutinho Costa. Parecer Técnico N¹0/2017 - SP/ MANAUS/ SEAP. Ministério Público Federal (MPF), 2017.

SOUZA LIMA, Antonio Carlos de Souza, SANTOS, Luis Felipe dos e RIBEIRO, Gustavo Lins (Orgs). Interculturalidade(s): entre ideias, retóricas e práticas em cinco países da América Latina. Rio de Janeiro: Associação Brasileira de Antropologia; Contra Capa, 2018.

SUÁREZ, María Matilde. Los warao. Caracas: Instituto Venezolano de Investigaciones Científicas (IVIC), 1968.

TARRAGÓ, Eduardo. Peça Pericial n. 01.2017/Antropologia/PR-RR/SP-BV/CRP-4. Ministério Público Federal (MPF), 2017.

VAQUERO, Antonio. Manifestaciones religiosas de los warao. Caracas: Universidad Católica Andrés Bello, 2001. 
VAQUERO, Antonio. Manifestaciones religiosas de los warao. Caracas: Universidad Católica Andrés Bello, 2001.

\& HEINEN, Dieter. Las Cuatro Culturas warao. In: Tierra Firme. Revista asbitrada de Historia y Ciencias Sociales. Caracas: No 71. Tercer trimestre, 2000.

WILBERT, Werner. Fitoterapia warao. Caracas: Instituto Caribe de Antropología y Sociología (ICAS). Fundación La Salle de Ciencias Naturales, 1995.

. La Etnobotánica warao en su contexto cultural. En: Memorias del Instituto de Biología Experimental. Vol. 2. Caracas. p. 23-26,1999.

WALSH, Catherine. Interculturalidad, colonialidade y educación. Revista Educación y Pedagogia, Medellín, Universidade de Antioquia, Facultad de Educación, vol. XIX, núm. 48, p. 25 -35, Mayo - Agosto, 2007a.

- "Interculturalidad y colonialidad del poder. Um pensamiento y posicionamiento 'otro' desde la diferencia colonial". In: CASTRO-GÓMEZ, S.; GROSFOGUEL, R. (eds.). El giro decolonial: refexiones para una diversidad epistémica más allá del capitalismo global. Bogotá: Siglo del Hombre Editores/Universidad Central, Instituto de Estudios Sociales Contemporáneos y Pontificia Universidad Javeriana, Instituto Pensar, 2007b.

revivir. 2009.

Interculturalidad crítica y pedagogía de-colonial: apuestas (des)de el in-surgir, re-existir y

Catherine. Interculturalidade, plurinacionalidade e descolonização: as insurgências político-epistêmicas de re-fundar o Estado. In: Tabula Rasa. ogotá/Colômbia n.9. JulhoDezembro, 2008.

.Interculturalidad crítica y educación intercultural. In: VIAÑA, Jorge; TAPIA, Luis; WALSH, Catherine. Construyendo Interculturalidad Crítica. La Paz: Convenio Andrés Bello, Instituto Interamericano de Integración, 2010.

Interculturalidade e decolonialidade do Poder um pensamento e posicionamento "outro" a partir da diferença colonial. In: Revista Eletrônica da Faculdade de Direito da Universidade Federal de Pelotas, V. 05, N.1, Jan.-Jul., 2019. 